University of South Carolina

Scholar Commons

$11-2011$

\title{
A Randomized Trial of a Diet and Exercise Intervention for Overweight and Obese Women from Economically Disadvantaged Neighborhoods: Sisters Taking Action for Real Success (STARS)
}

\author{
Sarah Wilcox \\ University of South Carolina - Columbia, swilcox@sc.edu \\ Patricia A. Sharpe \\ University of South Carolina - Columbia, SHARPEP@mailbox.sc.edu \\ Deborah Parra-Medina \\ Follow this and additional works at: https://scholarcommons.sc.edu/

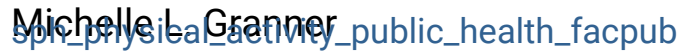 \\ SRate.qfitheoPublic Health Commons
}

\section{Publication Info}

Postprint version. Published in Contemporary Clinical Trials, Volume 32, Issue 6, 2011, pages 931-945.

Wilcox, S., Sharpe, P. A., Parra-Medina, D., Granner, M., \& Hutto, B. (2011). A randomized trial of a diet and exercise intervention for overweight and obese women from economically disadvantaged neighborhoods: Sisters Taking Action for Real Success (STARS). Contemporary Clinical Trials, 32(6), 931-945.

DOI: 10.1016/j.cct.2011.08.003

(C) Contemporary Clinical Trials, 2011, Elsevier

http://www.journals.elsevier.com/contemporary-clinical-trials/

http://www.sciencedirect.com/science/article/pii/S1551714411002047

NOTICE: This is the author's version of a work that was accepted for publication in Contemporary Clinical Trials. Changes resulting from the publishing process, such as peer review, editing, corrections, structural formatting, and other quality control mechanisms may not be reflected in this document. Changes may have been made to this work since it was submitted for publication. A definitive version was subsequently published in Contemporary Clinical Trials, [Volume \#32, Issue \#6, (2011)] DOI: 10.1016/j.cct.2011.08.003

This Article is brought to you by the Physical Activity and Public Health at Scholar Commons. It has been accepted for inclusion in Faculty Publications by an authorized administrator of Scholar Commons. For more information, please contact digres@mailbox.sc.edu. 


\title{
A Randomized Trial of a Diet and Exercise Intervention for Overweight and Obese Women from Economically Disadvantaged Neighborhoods: Sisters Taking Action for Real Success (STARS)
}

\author{
Sara Wilcox ${ }^{1}$, Patricia A. Sharpe ${ }^{1,2}$, Deborah Parra-Medina ${ }^{3}$, Michelle Granner ${ }^{4}$, and Brent \\ Hutto $^{2}$ \\ ${ }^{1}$ Department of Exercise Science, Arnold School of Public Health, University of South Carolina, \\ Columbia, South Carolina, USA \\ 2Prevention Research Center, Arnold School of Public Health, University of South Carolina, \\ Columbia, South Carolina, USA \\ ${ }^{3}$ Institute for Health Promotion Research, University of Texas Health Science Center at San \\ Antonio, San Antonio, Texas, USA \\ ${ }^{4}$ Division of Health Sciences, School of Community Health Sciences, University of Nevada, Reno, \\ NV, USA
}

\section{Abstract}

Background-Lower socioeconomic status at both the individual and neighborhood level is associated with increased health risks. Weight loss can reduce this risk, but few high quality weight loss studies target this population.

Objectives-STARS tests a culturally-appropriate, group-based behavioral and social support intervention on body weight and waist circumference in women from financially disadvantaged neighborhoods.

Design-A stratified (by BMI) randomized trial. Randomization to group was generated by a random numbers table with allocation concealment by opaque envelopes.

\begin{abstract}
Methods-Participants $25-50$ years who had a BMI $\geq 25 \mathrm{~kg} / \mathrm{m}^{2}$ and a waist circumference $\geq 88$ $\mathrm{cm}$ were recruited from 18 census tracts in Columbia, $\mathrm{SC}$ with high rates of poverty between November 2008 and November 2010. All participants received a dietary and exercise counseling session. Intervention participants then receive 16 theoretically-based and tailored weekly group sessions followed by 8 weeks of telephone maintenance counseling. Control participants receive 16 weekly health education mailings. Measurements correspond to baseline, post-group intervention, and post-telephone counseling, and for intervention participants, after a 12-week nocontact period. Measurement staff was blinded to group assignment.
\end{abstract}

(C) 2010 Elsevier Inc. All rights reserved.

"Corresponding author: Sara Wilcox, PhD, Professor, Department of Exercise Science, Arnold School of Public Health, University of South Carolina, 921 Assembly Street, PHRC $2^{\text {nd }}$ Floor, Columbia, SC 29208. Phone: 803-777-8141. Fax: 803-777-2504. swilcox@sc.edu.

Publisher's Disclaimer: This is a PDF file of an unedited manuscript that has been accepted for publication. As a service to our customers we are providing this early version of the manuscript. The manuscript will undergo copyediting, typesetting, and review of the resulting proof before it is published in its final citable form. Please note that during the production process errors may be discovered which could affect the content, and all legal disclaimers that apply to the journal pertain. 
Results-Participants ( $\mathrm{N}=155 ; \mathrm{n}=80$ intervention, $\mathrm{n}=75$ minimal intervention control) were primarily African American (86.5\%) and averaged 38.9 years with a mean BMI of $40.1 \mathrm{~kg} / \mathrm{m}^{2}$ and waist circumference of $115.4 \mathrm{~cm}$. Food insecurity was reported by $43 \%$ of participants.

Summary-STARS targets an underserved population with an innovative, tailored, and theoretically-grounded, group-based intervention followed by telephone maintenance. If effective, the approach has the potential to be feasible and cost-effective for community delivery.

\section{Keywords}

exercise; physical activity; diet; African American; health disparities; women

\section{Introduction}

Minority race/ethnicity and lower socioeconomic status (SES), at both the individual and neighborhood level, are associated with increased risk of morbidity and mortality for numerous health conditions [1, 2]. Risk factors for cardiovascular disease (CVD), the leading cause of death in the United States [3], include high blood pressure, high cholesterol, diabetes, smoking, physical inactivity, and obesity. African Americans and persons with lower socioeconomic status are more likely than other groups to have two or more CVD risk factors [4], and these groups also have higher rates of hypertension [3], poorly controlled diabetes [5], and obesity [6], and lower rates of physical activity participation [7], fitness [8], and healthy dietary practices [9]. Furthermore, among African American women, lower neighborhood SES has been associated with 10-year weight gain even after adjustment for individual-level variables [10].

A healthy diet, regular physical activity, and a healthy body weight are desirable targets for intervention studies because they are modifiable and, if changed successfully, can prevent and control many chronic diseases. Interventions that target these behaviors in underserved populations, however, must be sensitive to the larger socioeconomic forces that shape them including lower availability of healthy food options and greater availability and lower cost of less healthy food options [11], as well as less access to physical activity-related resources. Furthermore, important cultural factors likely must be considered, including desire and motivation (or lack of) to lose weight; cultural food preferences, symbolism, and traditions; and cultural perceptions regarding physical activity [12].

A large number of studies have targeted weight loss in overweight and obese samples [13]. Studies generally show maximal weight loss, using a variety of strategies, at six months followed by some but generally not complete weight regain over time. Although many studies have examined associations between low socioeconomic status and obesity-related factors, fewer interventions have specifically targeted disadvantaged populations. A recent meta-analysis set out to review weight loss interventions in minorities [14]. However, due to the small number of studies that included all-minority samples $(n=9)$, they chose to also include studies with samples that included at least 25 minority participants or were at least $50 \%$ minority $(n=15)$. Of the 24 studies reviewed, the majority were clinical-based $(n=19)$ rather than community-based $(n=5)$. The authors found that interventions $(n=6)$ that targeted three out of four strategies (energy consumption, energy expenditure, counseling or medication) were more successful than one- $(n=6)$ or two-component $(n=13)$ interventions. Kumanyika [12], who provided a commentary on this review as well as the state of weight control research in ethnic minorities, concluded that the evidence-base is "still rudimentary" (p. 585) and greatly in need of more high quality studies. Yancey et al. [15] conducted a review of community-based interventions with communities of color that focused on healthy eating and active living. Of the 23 interventions included, less than half presented outcome 
data. In addition, statistically significant effects were rare, and only five studies used a randomized design.

Since the time of these reviews, several additional studies have focused on weight in African Americans and socioeconomically disadvantaged populations. A subanalysis of weight loss by race and gender in the Diabetes Prevention Program found that black women lost significantly less weight than other race-gender groups in the intensive lifestyle intervention group $(-8.1 \%$ in white women, $-4.5 \%$ in black women), although they lost more weight than is typical of other studies of black women [16]. The authors discussed the importance of environmental and sociocultural factors that might have limited the success of the program. The Weight Wise program [17], examined a 16-week group weight loss intervention for low-income women, modeled after The Diabetes Prevention Program and PREMIER but designed to be more cost effective, found significant but fairly modest reductions in weight which proved to be cost effective [18]. Kumanyika and colleagues [19] formally tested the impact of social support and found that African American participants who enrolled in a weight loss program with a family member or friend did not lose more weight than those who enrolled alone; however, greater participation in the program and greater weight loss by the significant other was associated with greater weight loss in the participant. Still another study found no augmentation of weight loss when motivational interviewing was added to a culturally-targeted behavioral program, although the sample size was small [20]. Three other studies [21, 22, 23], two of which are ongoing [21, 23], have taken place in primary care settings, and a number of non-randomized studies have been conducted in African American churches [24, 25].

Thus, despite the moderate amount of research available on the antecedents and correlates of healthy diet and exercise among financially disadvantaged and ethnic/racially diverse populations, most of what we know of effective behavioral approaches is from research conducted entirely or predominantly with Caucasian women. It is unknown how, or if, these strategies can be reframed within a culturally appropriate community-based context, with significant input from the community via formative research, nor if extended support by telephone can lead to long-term maintenance of behavior change and weight loss. The purpose of this paper is to describe the development of such a study, Sisters Taking Action for Real Success (STARS). While the theoretical and behavioral principles employed in STARS are evidence-based, the adaptation and application of these principles to meet the personal, environmental, and economic challenges of this population of women has rarely been done. Socioecologic models of health behavior change contend that people have a greater chance of success if multiple levels of influence on behavior receive attention. The intervention in this randomized controlled trial will address multiple levels: individual and family-level behavioral change; participation in a group setting of mutual support and reciprocity; and engaging community contextual issues within a creative group-based, action-oriented approach to barriers and inequities (e.g., community action, enhanced resource utilization, self-help).

\section{Methods}

This study was funded by the NIDDK (DK074666) and is registered in clinicaltrials.gov (NCT01172340). The study protocol was approved by the Institutional Review Board at the University of South Carolina on 6/17/2007. CONSORT reporting guidelines were followed in this paper [26, 27].

\subsection{Study aims}

The primary aim of STARS is to test the effects of a 16-week behavioral/social support group-based intervention on body weight and waist circumference compared to a minimal 
intervention control group. This study has four secondary aims: (a) test the effects of the 16week group-based intervention on the secondary outcomes of physical activity, dietary composition, and dietary behaviors; (b) test the effect of an 8-week telephone-delivered maintenance intervention on primary and secondary outcomes; (c) assess long-term maintenance of primary and secondary outcomes after a 12-week no-contact maintenance phase that begins after the telephone maintenance phase ends; and (d) examine whether changes in psychosocial constructs consistent with our theoretical model mediate the relationship between the intervention and outcome measures at each of the measurement periods.

\subsection{Setting and population}

This study is being conducted in Columbia, SC. According to the 2000 Census [28], Columbia is the largest city in SC, with a total population of 116,278 , within a standard metropolitan statistical area (SMSA) of 536,691. Of persons naming one race, $46 \%$ of residents were African American (non-Hispanic) and 49\% Caucasian (non-Hispanic). Among all residents, $3 \%$ report Hispanic ethnicity. Almost one-quarter (22\%) of the city's residents are below poverty (compared to $14 \%$ for the state, which ranks 12th poorest in the nation), and $18 \%$ have less than a high school education. Among female-headed households with children under age 5,57\% live below poverty. Of 61 census tracts in the city, 18 tracts have at least $25 \%$ of all residents living below poverty (mean $39.1 \%$, range $=25 \%$ to $62 \%$ ). STARS participants were recruited from these 18 census tracts, which have a combined population of 44,317 and a median household income of $\$ 20,719$.

\subsection{Recruitment}

A community outreach approach was used to recruit participants. A community advisory board of women who live and/or work in service organizations in the neighborhoods within the identified 18 Census tracts was formed to provide guidance and assistance identifying recruitment strategies, contact persons, and venues, as well as to promote trust and research acceptability within the community. Contact persons from neighborhood associations, public housing, adult education, churches, day care centers, beauty salons, social service organizations, small businesses, physicians' offices and primary health care clinics posted recruitment fliers and made verbal referrals to the program. Project staff recruited participants at community meetings and events in the identified areas.

\subsection{Study design}

A schematic of the study design, including intervention activities and measurement periods, is shown in Figure 1. We proposed to randomize 180 women to the intervention $(n=90)$ or minimal intervention control condition $(\mathrm{n}=90)$ after they met eligibility requirements and provided baseline data. We enrolled and randomized one cohort each year for three years. For each year's cohort, two intervention groups were formed in order to keep the group size to around 15 women. Because many studies targeting underserved populations have reported retention difficulties, the enrollment goal was increased to accommodate losing up to onethird of the sample due to attrition at the final visit (i.e., final sample of 120 participants). Intervention group participants complete measurement sessions at four time periods: baseline (time 1), immediate posttest after 16 weeks of the group intervention (time 2), and delayed posttest after 8 weeks of the telephone maintenance intervention (time 3). Control group participants complete measurement sessions at these same times. Intervention group participants also complete an additional measure of long-term maintenance after 12 weeks of no contact (time 4). Women assigned to the control condition are offered an abbreviated group intervention ( 8 weeks in duration) after their final measurement (time 3 ) has been completed. 
A minimum of two weeks are required to complete an assessment so that each participant can wear an accelerometer for one week, receive three telephone interviews for 24-hour dietary recall, and receive in-person interviews and anthropometric measures. In order to allow time to recruit adequate numbers of women and complete measurements for all women, measurement periods are generally longer than two weeks (see Figure 1).

\subsection{Inclusion and exclusion criteria}

To be eligible for the study, women must (a) live within the identified economically disadvantaged census tracts; (b) have a body mass index (BMI) of at least $25 \mathrm{~kg} / \mathrm{m}^{2}$ and a waist circumference of at least 88 centimeters; (c) be between the ages of 25 and 50 years at their last birthday; (d) be English speaking; and (e) be willing to accept random assignment to condition.

Women are excluded from the study if they: (a) are pregnant; (b) are unable to participate in any type of moderate intensity exercise due to physical limitations; (c) have positive (risk) response(s) on the Physical Activity Readiness Questionnaire (PAR-Q) [29] and physician disapproval on the subsequent Physical Activity Readiness Medical Examination (PARMED-X) [30]; (d) have uncontrolled elevated blood pressure ( $\geq 140 / 90$ ); (e) have cognitive, visual, auditory, physical functional, or language impairment(s) that would preclude participation in group discussion, learning activities or data collection interviews; (f) have insulin-dependent diabetes; or (g) weigh more than 430 pounds (the limit of our scale).

Women who expressed an interest in enrolling in the study were screened by telephone for initial inclusion/exclusion criteria. If the woman appeared initially eligible, an in-person visit was scheduled to determine all inclusion/exclusion criteria and conduct baseline measurements. If the woman required medical clearance to participate or other needs were discovered (e.g., food insecurity, elevated depressive symptoms), appropriate referrals were made. For those women needing medical clearance, they were required to obtain approval prior to randomization or else were excluded. Women who were identified through the PAR-Q and/or blood pressure screening as being at elevated risk, but did not have a family physician, were helped to find a local clinic that accepts Medicaid or has a sliding fee scale for under- or uninsured patients.

\subsection{Randomization}

Randomization to group for each cohort occurred after baseline data collection was complete and all medical releases were obtained (where necessary); therefore, any attrition during the data collection period occurred before randomization. Stratified random sampling was used to ensure the groups contained similar numbers of women with a BMI $\geq 40.0 \mathrm{~kg}$ / $\mathrm{m}^{2}$ (the median in our first cohort of women). Using a random numbers table, the biostatistician designated 60 slips of paper as intervention (labeled "Group A") or control (labeled "Group B") and placed them into opaque envelopes (30 intervention, 30 control). Two boxes were prepared: one for women with a BMI $<40.0 \mathrm{~kg} / \mathrm{m}^{2}$ and one for women with a BMI $\geq 40.0 \mathrm{~kg} / \mathrm{m}^{2}$. After the end of the visit in which the participant received her diet and exercise counseling session (and after she received medical approval if needed), she went to a separate room and another staff member selected and opened the next envelope from the appropriate box in the participant's presence. This randomization protocol was typically conducted by the Program Coordinator or Principal Investigator, and occasionally by another member of the intervention staff (none of whom take follow up measurements). Upon notification of the group assignment, the staff person described what would happen next and entered the woman's name, participant number, and group assignment into a tracking database. Participants assigned to "Group A" were told that group sessions would begin shortly (date provided) whereas those assigned to "Group B" were told that they 
would receive weekly health education materials by mail for 16 weeks and would receive information about the group weight loss sessions at their next study visit (time 2). The terms "intervention" and "control" group were not used in the randomization scripts or in the informed consent form.

\subsection{Intervention}

2.7.1 Intervention overview-The development of the intervention was guided by our conceptual model, what we learned from the formative focus groups, as well as by the broader exercise, diet, and weight loss literatures. The intervention includes behavioral strategies shown to be effective in the areas of exercise, healthy eating, and weight loss [31], but with content and experiential learning activities tailored to the financially disadvantaged population we targeted. The major components of the intervention included one-on-one counseling with individual goal setting (provided to both intervention and control participants) along with group sessions and maintenance telephone counseling (provided only to intervention participants).

2.7.2 Conceptual model-The conceptual model for the intervention is shown in Figure 2 . The behavioral strategies emphasized in the groups were based on principles of Social Cognitive Theory (SCT) [32], Social Support [33], and Relapse Prevention [34]. SCT, which emphasizes the interaction between an individual, his/her environment, and behavior, has guided numerous successful behavior-change interventions. A key construct in SCT is self-efficacy, or one's confidence to execute a behavior. High self-efficacy, combined with positive expectations and evaluations about expected outcomes of the behavior change, enhance the success of achieving and maintaining change. Self-efficacy is enhanced by successful experiences with behavior (facilitated by gradual changes), observation of successful role models, verbal persuasion or encouragement, and physiological states (e.g., positive mood, enjoyment). Other important constructs of SCT include behavioral capacity (trying new exercises, engaging in meal planning), emotional coping responses (training in stress management and learning how to refute cognitive distortions), and self-regulation (self-monitoring, setting goals, problem solving, self-rewards).

In addition, the four major types of social support that assist a person in undertaking behavior change [33] are emphasized: instrumental (tangible aid such as childcare or transportation), appraisal (information to assist in self-assessment - e.g., How am I doing?), emotional (providing understanding and a sense of acceptance), and informational support (providing knowledge to help in behavior change). Participants receive these types of social support from the interventionists and other group members, and they also learn how to identify and request the support they need outside of the group setting.

Relapse prevention strategies [34] teach the individual skills to anticipate and resist situations that could lead to relapse (e.g., eating out with friends) as well as how to view lapses in behavior as normal rather than catastrophic, thereby avoiding total relapse and return to previous behavioral patterns. These strategies also help individuals learn effective ways to manage stress so that stressful situations do not prompt eating or sedentary behavior as coping responses. Identifying potential problem situations and planning effective coping strategies, as well as opportunities for practice and feedback of the skills, are incorporated into the sessions.

2.7.3 Intervention development: focus groups-A series of focus groups were conducted to guide the tailoring of the intervention to the target population. Four focus groups were conducted with African American women who resided in the targeted census tracts: two pertained to physical activity/exercise $(n=14)$ and two pertained to healthy 
eating and weight loss $(n=19)$. The facilitator's guides were pretested prior to implementation with a group of four women. Eleven questions in the physical activity guide focused on such topics as barriers to physical activity, ways to motivate women to be active, past history of experiences with physical activity (including reactions of significant others), perceptions of a physically fit woman, cultural and neighborhood influences on physical activity, and desired program elements. Eleven questions in the healthy eating and weightloss guide focused on such topics as perceptions of what constitutes "eating healthy," past history of experiences with healthy eating and weight loss (focusing on successes and difficulties), perceptions of a woman who wants to lose weight, barriers to healthy eating for weight loss, ways to help and motivate women to eat healthy, desired program elements, and ways that food cost can influence eating and shopping habits.

Physical activity focus group findings: Focus groups uncovered the major barriers, supportive or motivating factors, programmatic suggestions, and other important themes as related to physical activity and exercise. Similar to what has been reported in other studies of African American women, the major barriers to exercise included family and other competing responsibilities, perceptions that their community was unsafe for outdoor exercise and lacked places to exercise, the high cost of gym memberships, and a woman's low motivation to exercise. Somewhat unique to this study, women also discussed experiences and concerns about being ridiculed by others, because of their body size, when exercising. The women believed receiving social support from a group or exercise partner, focusing on health benefits, learning to incorporate exercise into their daily lives, and involving children in their exercise would help to motivate them to exercise. Participants provided suggestions for the type of exercise program they wanted. They wanted a free or affordable group-based program (held in the evenings) that provided exposure to a variety of exercises. They suggested that the program provide incentives, transportation (or be close to bus line), and childcare. The program should include education about exercise and healthy eating, should use music, and should include regular weigh-ins. A suggestion unique to this population was that they wanted sessions held in a location without windows or mirrors. Finally, several instructor/facilitator characteristics were important to women: not too skinny, nonjudgmental, ability to work with different people, patient, supportive, outgoing, motivating, and caring. Several other important and unique themes were raised. Women discussed their desire to retain their "curves," they discussed how they were satisfied with a larger body size, and they described the need for immediate and continuous results in order to motivate them to continue with the program.

Healthy eating focus group findings: Similar barriers were noted in the healthy eating/ weight loss focus groups (competing responsibilities, high cost, unsupportive family and friends). Other barriers were more unique to healthy eating. For example, "low calorie," "low fat," and "healthy" foods were perceived as unappealing, and unhealthy foods were often used for comfort, especially when experiencing interpersonal stress. Similar to exercise, health benefits (including mental health benefits and the diagnosis of a medical condition) and social support were viewed as motivating factors to eat healthy and lose weight. Women discussed how meal planning, making small gradual changes, and having the right "mindset" were helpful. Women also believed that eating better would help their children to prevent obesity and other health problems. Programmatic suggestions not previously mentioned included nutrition education, cooking demonstrations and tastings, tips for inexpensive healthy foods, instruction in meal planning, address stress eating and stress management, and inclusion of a dietician as one of the instructors. Women in these groups also discussed the body image issue noted in the exercise group, and also stated that it is difficult to stick with a weight loss program, especially if a rigid diet plan is used. 
As described in detail in Section 2.7.5, the group weight loss sessions incorporated the majority of these themes and programmatic suggestions.

2.7.4 Individual counseling session: intervention and control group-In order to promote program acceptability in the community, it was important that all women receive some level of intervention related to physical activity and diet. Thus, all participants in the study (intervention and control groups) received an initial one-on-one in-person physical activity and dietary counseling session. For the dietary session, a dietician counseled all participants for about 30 minutes. Participants received a report that outlined the results of their 24-hour dietary recalls (described in a later section) and were counseled to set an initial goal of a $10 \%$ reduction in their weight at a rate of about one to two pounds per week. Women received a suggested meal plan that was tailored to their caloric needs. Tip sheets on various topics were used to support counseling messages (e.g., fats and oil, weight loss tips). The dietary recommendations incorporated evidence-based eating plans such as the DASH diet [35]. The later part of the session was devoted to creating a plan for change (identifying one or two initial goals for change), identifying potential barriers to this plan, and identifying strategies to overcome these barriers. All participants received a community resource guide related to healthy eating. Participants who were diabetic also received a diabetes tip sheet. This tip sheet was created by two doctoral-level nursing faculty with expertise in diabetes care and was based on information provided by the American Diabetes Association (www.diabetes.org/). The tip sheet strongly emphasized the need for women to consult with their doctor to monitor the impact of weight loss on their diabetes control. It also provided information regarding warning symptoms (hyper and hypoglycemia), safety tips, and the importance of monitoring glucose levels and foot care. The health care providers of these women, as well as other women with health conditions, also received a letter informing them of their patient's participation in the trial, a description of the intervention, and a request to contact the study principal investigator or registered dietician with questions or concerns. Participants provided signed consent for the research staff to communicate with their health care providers regarding their participation in the study.

For the physical activity session, all participants received 30 minutes of counseling from an exercise specialist. This session covered moderate-intensity exercise, physical activity recommendations (30 minutes/day, 5 days/week), and the option to accumulate exercise in 10- or 15-minute bouts. Tip sheets were provided to support these key counseling messages. Participants also received a report that summarized their physical activity results from the seven days in which they wore an accelerometer (described in a later section). Like the dietary counseling portion, the later part of the session was devoted to creating an exercise plan, identifying potential barriers to this plan, and identifying strategies to overcome these barriers. All participants received a list of community resources related to exercise, an exercise safety tip sheet, and a chair exercise routine (designed for women who may not be ready for brisk walking).

\subsubsection{Group-based behavioral sessions: intervention group-Group-based}

interventions are common in weight-loss intervention studies and were a preferred mode of delivery for women in our focus groups. We designed a 16-week group-based program that was based on our conceptual model and tailored to the unique issues of the target population, as informed by the focus group findings. An outline of the 16 sessions is presented in Table 1. Interventionists include a health educator, an exercise specialist, and a staff member with a master's degree in food and nutritional sciences. At least two interventionists are present at every session. Participants receive a stipend for attending each session that they can apply to transportation and/or childcare costs. Sessions are held within walking distance of a bus stop and at a location that has free and ample parking. The sessions are held in a large room that includes a demonstration kitchen, chairs for group 
discussion, and open space for exercise. Numerous incentives and tools are provided to women over the course of the 16 weeks. These include measuring cups, measuring spoons, lunch bags, water bottles, recipe booklets, pedometers, sport watches, resistance bands, yoga mats, exercise DVDs, relaxation/stress reduction DVDs, exercise towels, and tote bags. Participants receive binders to hold all of their class handouts and receive a weekly journal to record goals and to self-monitor.

The sessions address barriers in the environment and economic challenges, such as finding a safe and affordable way to exercise (e.g., identifying public resources such as parks and recreation centers near the woman's home or worksite) and eating healthfully on a limited budget and with time constraints (e.g., economical shopping and meal planning). Women learn how to adapt existing recipes to be healthier. Group sessions include cooking demonstrations and tastings of foods that use affordable and available ingredients. These tastings help to counter the myth that healthy food does not taste good.

Demonstrations and opportunities for participation in various types of exercise are also provided during the sessions. To provide exercise opportunities that can be done at home for convenience, safety reasons, or in times of bad weather, all women receive an exercise DVD geared for women who are at a beginner fitness level that is led by an African American instructor (our baseline assessment found that all women had a DVD player and a 2006 survey of US households found that $81.2 \%$ owned at least one DVD player [36]). Ample time during group sessions is provided for group discussion and support. Group-based problem-solving activities support the women to identify their own challenges, develop creative solutions, use available resources and supports, or engage in community action to bring about changes. Women learn and practice how to negotiate with family members regarding meals and how to obtain needed support. Group activities are designed to increase self-efficacy, develop group support, and facilitate a context of reciprocity.

2.7.6 Telephone maintenance counseling: intervention group-After time 2 measurements are complete, an additional eight weeks of weekly telephone contact is provided to all intervention women. These calls provide an opportunity for women to receive positive reinforcement and to obtain support for continued behavior change. A telephone support script was created based on similar scripts used in other behavior change programs [37, 38]. All study participants have a phone. Data from 2010 indicates that only $2 \%$ of US households had neither a landline nor a cell phone [39].

Each call begins with a health assessment to ensure that no new health issues or symptoms occurred since the last contact. The women chose which behavior they wish to discuss first (e.g., exercise or healthy eating first, followed by the other behavior). For both behaviors, the interventionist assesses progress toward the goal set in the previous call (or in the case of the first call, an initial goal is set), whether the woman continued to use her journal to selfmonitor, what went right or facilitated the target behavior over the past week, and what got in the way of the target behavior or made it difficult in the past week. When a woman identifies a barrier to behavior change, the interventionist guides her in problem-solving to overcome the barrier. Women are also asked to anticipate barriers in the upcoming week and how they could be addressed (relapse prevention). Finally, the woman is asked to set new goals that are specific, realistic, and measurable. After all of these behavioral topics are addressed, the interventionist assesses weight loss progress, satisfaction, and goals. The main points of the call are then summarized back to the participant, and the next call time is confirmed.

2.7.7 Weekly health education mailings: control group-Women in the control group receive the same frequency of contact (but via mail) as do intervention women. This 
design was chosen in order to establish a consistent relationship with women in both groups so as to maximize retention rates. Each week during the 16 weeks while the intervention participants meet in group behavioral sessions, the control group receives by mail printed health education materials developed by health and governmental organizations, along with a small incentive. Examples of topics for the print materials include sleep, hand-washing, stroke, and mammograms. The materials do not emphasize dietary change, physical activity, or weight loss.

2.7.8 Delayed group-based behavioral sessions: control group-After the time 3 data collection session, control participants are invited to participate in an abbreviated (8session) group-based program, based upon what is provided to intervention participants. Although it increased cost and time, offering the intervention to the control group, after a delay, is essential in community-based projects to ensure acceptability of the research to the community.

\subsection{Measures}

To the extent possible, measurement staff members are blind to participant intervention assignment for all follow up visits. Intervention staff members assist in measurement sessions only at the baseline visit before random assignment. One staff member, however, is involved in the randomization and in subsequent measurement visits, but she does not deliver the intervention to participants. Primary and secondary outcome measures are completed at all measurement visits. Participants receive incentives for completing the measurement session, returning their accelerometer, and completing the 24-hour dietary recalls.

2.8.1 Screening measures-The following three measures are not research outcomes but are used during the screening visit to identify women who might need to be excluded, who need referrals for medical clearance or care, or who need assistance locating emergency food and/or food stamps.

Physical Activity Readiness Questionnaire (PAR-Q): The PAR-Q [29] is a seven-item tool for initial screening of adults who need medical clearance to participate in a moderate intensity physical activity program. Women who answer yes to one or more questions but wish to enroll were required to see their physician for medical clearance to participate. Staff assisted women who did not have a physician through referral to clinics that accept Medicaid or under- or uninsured patients.

Blood pressure was measured three times over the course of the 90-minute visit, with quiet sitting prior to each reading [40]. Participants with readings suggestive of hypertension $(\geq 140 / 90)$ [40], based on the average of the three readings, were required to receive medical clearance to participate and were referred for evaluation for hypertension. The Omron HEM-711DLX blood pressure monitor was used to obtain the three measurements. If a participant's arm was too large for this monitor, the LifeSource UA-789 digital monitor with the AccuFit extra large cuff was used instead.

Food security was assessed with the six-item Short Form of the US Household Food Security Module [41]. This assessment was included for ethical reasons to insure that no woman who volunteers to participate was in need of food. If a woman answered affirmatively to more than one item, a staff person discussed food security with the participant, and if indicated, referred her to local food banks for emergency supplies and to the Department of Social Services for a Food Stamp application. All women received a list 
of community resources for emergency financial, clothing and food assistance, social services, mental health services, and medical clinics that serve the uninsured.

\subsubsection{Primary outcome measures}

Weight: Weight was measured with a Seca 882 scale to the nearest tenth of a pound.

Waist Circumference: Using the measurement protocol from the National Health and Nutrition Examination Survey (NHANES) [42], waist circumference was measured to the nearest tenth of a centimeter just above the ilium by a trained staff member. A waist circumference measurement of $83 \mathrm{~cm}$ and above indicates elevated disease risk [43, 44]. To ensure that enrolled women were in need of significant weight loss, they were required to have a waist circumference of at least $88 \mathrm{~cm}$ to participate in the study.

\subsubsection{Secondary outcome measures}

Dietary intake: The dietary outcomes for this study are total caloric intake; percent of calories from total fat, saturated fat and trans fat; and servings per week of fruits and vegetables determined through three, unannounced multiple-pass 24-hour recalls. During the baseline visit, participants received one-on-one training in estimating portion sizes. Our training was based on existing training methods that use the Food Portion Visual (The 2D Food Portion Visual, 1996, Nutrition Consulting Enterprises, Framingham, MA) [45], but was substantially enhanced to include a one-on-one 20-minute session with the use of food models, utensils, cups, bowls, and plates. This training was pretested during our formative work to confirm its applicability to the study population. Minor edits were made to the script. Directly after the training, participants completed their first 24-hour recall by telephone during the measurement visit (an off-site registered dietician calls the study office and completes the call). The remaining two calls were completed by telephone within the next 15 days. The Nutrient Data System for Research (NDS-R, Version 5.0_35) software (licensed from the Nutrition Coordinating Center at the University of Minnesota) was used for estimations. Interviewers are a team of experienced and trained master's level, registered dietitians. The average daily intake across the three interviews was computed. Twenty-four hour recalls have established validity and reliability [46].

Objective measurement of physical activity: The ActiGraph accelerometer (GT1M model, ActiGraph, LLC, Fort Walton Beach, FL) was used to objectively measure physical activity at each measurement period for seven days. This monitor is a uniaxial accelerometer that measures acceleration in the vertical plane ranging in magnitude from 0.05 to $2.00 \mathrm{Gs}$ with frequency response of 0.25 to $2.50 \mathrm{~Hz}$. Participants were instructed to wear the ActiGraph on the right hip during all waking hours (except while in water) for seven consecutive days. They also kept a physical activity diary over the same period. A 60-second epoch (time interval) was used. The GT1M model is the newer version of the extensively validated 7164 Model [47]. The actigraph protocol and physical activity diary can be obtained at http://prevention.sph.sc.edu/tools/index.htm.

In order for each woman's data to be considered adequate, she was required to wear the accelerometer for at least 4 days during a week and at least 10 hours per day. For adults, three to four days of monitoring is required to achieve acceptable reliability estimates [48] and four days were required for the 2003-2004 NHANES [49]. Ten hours per day is a common cut-point in accelerometer studies [50], and was the cut-point used in NHANES [49].

We propose to use the cutpoints defined by Lopes et al. [51] to classify activity counts as sedentary (<1.5 METs; <200 counts/minute), light (1.5 to 1.9 METS; 200-1239), moderate 
(3.0-5.9 METS; 1240-2399), or vigorous ( $\geq 6$ METS; $\geq 2400$ ). These cutpoints were validated for overweight and obese participants. If other validity studies with population groups similar to the STARS participants are published prior to when our data analyses are conducted, they will be considered.

Estimated cardiorespiratory fitness: We estimated the participants' level of cardiorespiratory fitness based on an equation by Jurca and colleagues [52]. Estimates from this equation have been shown to correlate highly with maximal and submaximal exercise tests in three different samples that included men and women ages 20-70 (multiple correlation coefficient ranged from 0.76 to 0.81 ). Participants are asked to choose one activity category (out of 5) that best describes their usual pattern of daily physical activities. These categories are assigned physical activity scores of 0.00 (level 1), 0.32 (level 2), 1.06 (level 3), 1.76 (level 4), or 3.03 (level 5). Their estimated MET level of cardiorespiratory fitness is then calculated as: $[$ Gender $($ women $=0$, men $=1) \times 2.77]-[$ age $\times 0.10]-[$ BMI $\times$ 0.17 ] - [resting heart rate $\times 0.03]+$ [physical activity score $\times 1.00]+$ [constant of 18.07]

Low-fat eating and emotional eating practices: Eight items from the low-fat eating and four items from the emotional eating subscales of the Eating Behavior Patterns Questionnaire [53] were administered. The wordings of several items were modified very slightly. These subscales have been shown to have acceptable internal consistency (alpha $=$. 84 and alpha $=.77$ for the two subscales, respectively). The measure has demonstrated construct validity with African American women.

Fast food frequency: The frequency of fast food visits in the past 7 days was assessed with a question from the Early Childhood Longitudinal Study [54]. Participants were asked how often in the past 7 days they ate a meal or a snack from a fast food restaurant (examples of fast food restaurants were provided).

\subsubsection{Mediating variables}

Exercise self-efficacy: The Exercise Self-Efficacy Questionnaire [55] consists of 14 items to rate confidence to exercise (ranging from $0 \%$ to 100\%) when faced with commonly-cited barriers (e.g., when tired, during bad weather). Ratings were averaged to form a composite scale score. This scale was found to have construct, criterion-related, and convergent validity and high internal consistency reliability $(\alpha>.90)$ across age, race, gender, and education subgroups, and was significantly and positively associated with physical activity level [56].

Self-efficacy for healthy eating: An 8-item measure developed to assess self-efficacy for eating a low fat diet in financially disadvantaged women was modified to assess selfefficacy for "making healthy food choices, such as choosing fruits or vegetables, choosing lower fat foods, and watching how much you eat" when faced with common barriers (e.g., when upset, eating out at a restaurant with others). This scale has three domains: positive affect, negative affect, and availability. The original scale has demonstrated construct and convergent validity, as well as internal consistency reliability $(\alpha \geq .82)$ [57].

Social support: Two 11-item scales assessing social support (one related to healthy eating and another for exercise) were developed and evaluated. Participants were instructed to think about the most recent time they tried to engage in the target behavior and to report how often "family members, friends, co-workers, or anyone else close to you" engaged in 11 supportive behaviors, with response options being $1=$ not at all, $2=\mathrm{a}$ little, $3=$ somewhat, $4=$ quite a bit, and $5=$ very much. These scales have construct validity and internal 
consistency reliability, with all factor loadings greater than 0.60 and all coefficient alphas exceeding 0.90 in a sample of middle-aged women (60\% African American) [58].

Goal setting, restructuring plans, and relapse prevention and maintenance: A 16-item instrument was administered to assess goal setting (6 items), restructuring plans (4 items), and relapse prevention and maintenance (6 items) [59]. Although this measure was developed to capture constructs important in physical activity interventions, the questions do not make reference to physical activity. The relapse prevention and maintenance scale and the goal setting scales have been reported to have acceptable internal consistency (.70 to .79) and test-retest reliability for three time periods ( 0 to 6 months, 0 to 12 months, 6 to 12 month) (.59 to .76). The restructuring plans scale, however, had lower internal consistency (. 49 to .60) but similar levels of test-retest reliability as the other two subscales (.57 to .66).

\subsubsection{Other variables}

Sociodemographic characteristics: Age, educational status, race, Hispanic ethnicity, employment status, health insurance coverage, marital status, and number of children less than 18 years of age at home were assessed with self-report questions.

Depressive symptoms: Participants completed the widely-used 10-item [60] Center for Epidemiological Studies Depression Scale (CES-D) [61]. Participants rated the frequency with which they experienced symptoms of depression during the past week. Possible scores can range from 0 to 30 with higher scores indicating greater depressive symptoms.

\subsection{Data Safety and Monitoring}

The funding agency did not require a data safety and monitoring board due to the low-risk nature of the intervention; however, a Data Safety Monitor reviews quarterly reports of enrollment, recruitment, data management and security, attrition and any reports of adverse events (no adverse events have been reported to date). As part of the data safety plan, symptoms and health status are assessed at each measurement. If a potential adverse event is reported or discovered by the staff at another time (e.g., group session, study reminder call), the Principal Investigator (PS) is notified and an adverse events form is completed within 24 hours. This form captures the incident or symptoms and assesses the event in terms of severity, association with the intervention, and duration (e.g., resolved or ongoing). The Principal Investigator reports adverse events to the university's Office of Research Compliance via an electronic reporting system. In addition, all investigators, staff, and students are required to maintain up-to-date certification in research ethics and human subjects.

\subsection{Process evaluation}

The process evaluation assesses reach, attendance and participation, dose, fidelity (implementation integrity), and compatibility [62]. All intervention contacts (groups and telephone calls) are audio recorded. Interviews, questionnaires, tracking databases, and observational ratings are used to assess the components of the process evaluation.

\subsection{Sample size justification}

Sample size was chosen to provide greater than $80 \%$ statistical power to detect differences between intervention and control groups for each of the primary anthropometric outcomes as well as secondary behavioral outcomes. Our own research data and various published studies were consulted for estimates of the effect sizes from physical activity and nutrition interventions to guide sample size determination. Alpha was set at 0.05 and our calculations allowed for the loss of up to one-third of the sample due to attrition (remaining $n=120$ ). 
With these assumptions, we had 0.996 power to detect a $2.0 \mathrm{~kg}$ difference in weight between groups (effect size $=0.85$ ) and 0.942 power to detect a $2.6 \mathrm{~cm}$ difference in weight circumference between groups (effect size $=0.65$ ). Our power was at least 0.89 to detect expected group differences in fruits and vegetables ( 0.43 servings per day), total kilocalories (449 kcal/day), percentage of kilocalories from fat (6.5\%), and physical activity $(36.2 \mathrm{~min} /$ day).

\subsection{Statistical analyses}

Prior to inferential procedures, extensive descriptive analyses and examination of distributions will be conducted for all variables at each time point in the intervention and control groups. The primary analysis will be an analysis of covariance (ANCOVA) comparing each outcome at immediate post-test by group assignment, adjusting for the baseline value and potential confounding variables. An analysis for each outcome will use baseline, immediate post-test, and delayed posttest ( 3 measurement points) to estimate a growth curve model [63]. This procedure can accommodate missing data at one or more time points while testing for statistically significant associations between group assignment and individual trajectory parameters in the study population. Both the ANCOVA and mixed models will be estimated separately for weight and waist circumference. In addition, growth curve models for the four measurement points available in the intervention group will assess longer-term maintenance of the intervention effects. Secondary models identical to the primary analyses will examine physical activity, total energy intake; percent of calories from total fat, saturated fat and trans fat; fruit and vegetable intake; self-efficacy for diet and exercise; social support for diet and exercise; and behavior skills for healthy diet and exercise.

Attrition-To examine effects of attrition, we will compare all baseline demographic, cognitive, and behavioral variables of participants lost to follow-up with baseline data of the cohort, to determine possible differential (by treatment condition) attrition. Presence of differential attrition (difference in dropouts between treatment conditions) will be considered a threat to internal validity. Analysis for the primary and secondary hypotheses will be done under the intent-to-treat principle with missing data handled by the methodology proposed by Little and Yau [64].

Mediation analyses-Baranowski and colleagues [65] have noted that few interventions measure or assess the impact of theoretically suggested mediating variables (e.g. social support, self-efficacy) on behavior changes. This study assesses self-efficacy for healthy eating and exercise as well as social support for healthy eating and exercise. In addition, the process evaluation will assess program fidelity and others factors that could affect the intervention's success. Mediation analyses will be conducted as outlined by MacKinnon [66]. Asymmetric confidence limits based on the distribution of the product $\left(\alpha^{*} \beta\right)$ will be constructed using the PRODCLIN program [67]. This approach has been shown to be more powerful than other analytic approaches in simulation studies [68].

\section{Results}

\subsection{Participant recruitment}

Figure 3 shows the flow of participants through the recruitment and randomization phase of the study. A total of 746 telephone inquiries were received to obtain the final sample of 155 participants ( $21 \%$ yield). We completed telephone screenings with $88 \%$ of those who made initial inquiries. Only $47 \%$ of those remained potentially eligible after the telephone screen. The most common reasons for ineligibility included not residing in the targeted Census tracts $(66 \%)$, not falling between 25 to 50 years of age (17\%), being unable to attend study 
visits or sessions (logistics or schedule, $6 \%$ ), and not being overweight (6\%). Of those who were initially eligible by telephone, $75 \%$ were consented and attended the first measurement visit; $25 \%$ did not show up for the visit or cancelled the visit. Prior to randomization, but after the baseline measurement was conducted, $12 \%$ of consented participants were excluded from the study, largely due to medical contraindications (81\%) and $20 \%$ did not attend the visit that included randomization. Thus, $68 \%$ of those consented and measured at baseline were randomized to an intervention condition.

\subsection{Participant characteristics}

Demographic and health-related baseline characteristics of the study sample are presented in Table 2. Intervention and Control participants did not differ significantly $(p>.05)$ on any characteristic at baseline. Most participants (86\%) self-identified their race as Black or African American, and less than three percent reported Hispanic ethnicity. Participants averaged about 40 years of age and most were college educated and employed. Nonetheless, $43 \%$ of the sample reported food insecurity. The largest proportion of women were never married (40\%), followed by married (23\%). Eighty percent of participants reported having health insurance of some type. By design, all women were overweight $(6 \%)$ or obese $(94 \%)$ with average waist circumference readings substantially above the at-risk range. The most common chronic health conditions reported by participants were hypertension (26\%), arthritis (14\%), heart disease (10\%), and diabetes (9\%).

\section{Summary}

Ethnic minorities and those who are of lower socioeconomic status, at both the individual and environment level, are at increased risk for health-related morbidity and mortality [1,2]. Yet these individuals are underrepresented in exercise, dietary, and weight loss interventions $[12,14]$, and there is some evidence that African American women do not respond as well to weight loss interventions as other race-gender groups $[12,15,16]$. This theoretically- and community-based randomized trial will examine the impact of a tailored diet and exercise intervention on weight loss, waist circumference, and dietary and exercise behaviors in a sample of women residing in financially disadvantaged neighborhoods. A limitation of our study should be considered: the requirement for several study visits may reduce generalizability as initially less motivated participants may have been screened out due to nonattendance at study visits.

Nonetheless, the strengths of the study design include randomization to intervention group, state-of-the-art measures of both exercise and diet (very rarely have accelerometers been used to capture physical activity in weight loss interventions), a unique analysis plan (growth curve modeling), inclusion of potential mediating variables, inclusion of a detailed process evaluation, and inclusion of a no-intervention maintenance period. Engaging a community advisory board of women who live in and/or work in service organizations in our target neighborhoods was also a unique aspect of the study. Their involvement helped us to develop a more relevant and tailored approach to the research, enhanced recruitment activities, and helped to garner trust and acceptability of the research within the community. The intervention is also unique in a number of ways. First, it specifically targets women who reside in disadvantaged neighborhoods, as defined by the Census. The study thus targets an important segment of the population and addresses multiple levels of change, including individual and family-level behavioral change; participation in a group setting of mutual support and reciprocity; and engaging community contextual issues within a creative groupbased, action-oriented approach to barriers and iniquities. Second, the use of formative work and the inclusion of a community advisory board help to ensure that the intervention is tailored to the unique circumstances of this population. Third, the intervention includes a group-based format for the initial period and then transitions to telephone-based support for 
the maintenance period. Most interventions use just one mode of delivery, particularly in African American samples. This dual-approach could be more effective and efficient at sustaining behavior change. Finally, the intervention promotes the gradual implementation of healthier dietary choices and exercise and the reduction of less desirable foods and sedentary behavior through behavioral strategies and does not stress calorie counting. This type of healthy lifestyle approach may be more feasible, palatable, and sustainable for the target population. The participants recruited into this study were experiencing substantial health risks and could benefit greatly from lifestyle change. Although we proposed rigorous and time-intensive outcome measures for this efficacy study, which thereby necessitated a longer recruitment and measurement period, these measures would not be necessary if the program were to be delivered in clinical or community settings. We believe the intervention approach has the potential to be feasible and cost-effective for community delivery.

\section{Acknowledgments}

Statement of financial support: The project described was supported by Grant Number DK074666 from the National Institute of Diabetes and Digestive and Kidney Diseases. The content is solely the responsibility of the authors and does not necessarily represent the official views of the National Institute of Diabetes and Digestive and Kidney Diseases or the National Institutes of Health.

We would like to thank all of the women who have participated in STARS and the members of the Community Advisory Board. We also wish to thank the many staff and students who have made contributions to the study (listed in alphabetical order): Barbara Ainsworth, Jorge Banda, Jean Butel, Shalanda Bynum, Dara Brown, Jvettra Devlin, Kathy Dhotre, Andrea Domas, Kara Goodrich, Jennifaye Green, Shericka Harris, Tammy Harris, Leigh Hart, Rosie Hopkins-Campbell, Tom Hurley, Brent Hutto, Hiluv Johnson, Sonya Jones, Violet Lindstrom, Gayenell Magwood, Robert Moran, Jeremy Ponds, Suhasini Reddy, Laura Rooney, Veena Seshadri, Robin Shook, Shelly Smith, Liliana Stoisor-Olsson, Donna Strong, Mary Ellen Suitt, Mia Taylor, Sherretta Thomas, and Ellen Wingard.

\section{References}

1. Lantz PM, Pritchard A. Socioeconomic indicators that matter for population health. Prev Chronic Dis. 2010; 7:A74. [PubMed: 20550832]

2. Coogan PF, Cozier YC, Krishnan S, Wise LA, Adams-Campbell LL, Rosenberg L, et al. Neighborhood socioeconomic status in relation to 10-year weight gain in the Black women's health study. Obesity (Silver Spring). 2010; 18:2064-2065. [PubMed: 20360755]

3. American Heart Association. Heart Disease and Stroke Statistics - 2010 Update. Dallas, TX: American Heart Association; 2010.

4. Sharma S, Malarcher AM, Giles WH, Myers G. Racial, ethnic and socioeconomic disparities in the clustering of cardiovascular disease risk factors. Ethn Dis. 2004; 14:43-48. [PubMed: 15002922]

5. Bonds DE, Zaccaro DJ, Karter AJ, Selby JV, Saad M, Goff DC Jr. Ethnic and racial differences in diabetes care: The Insulin Resistance Atherosclerosis Study. Diabetes Care. 2003; 26:1040-1046. [PubMed: 12663570]

6. Flegal KM, Carroll MD, Ogden CL, Curtin LR. Prevalence and trends in obesity among US adults, 1999-2008. JAMA. 2010; 303:235-241. [PubMed: 20071471]

7. Centers for Disease Control and Prevention. [Accessed February 8, 2011] US Physical Activity Statistics. 2007. Available at: http://apps.nccd.cdc.gov/PASurveillance/DemoComparev.asp

8. Wang CY, Haskell WL, Farrell SW, Lamonte MJ, Blair SN, Curtin LR, et al. Cardiorespiratory fitness levels among US adults 20-49 years of age: findings from the 1999-2004 National Health and Nutrition Examination Survey. Am J Epidemiol. 2010; 171:426-435. [PubMed: 20080809]

9. Liao Y, Tucker P, Okoro CA, Giles WH, Mokdad AH, Harris VB. REACH 2010 Surveillance for Health Status in Minority Communities --- United States, 2001--2002. MMWR Surveill Summ. 2004; 53:1-36. [PubMed: 15329648]

10. Coogan PF, White LF, Adler TJ, Hathaway KM, Palmer JR, Rosenberg L. Prospective study of urban form and physical activity in the Black Women's Health Study. Am J Epidemiol. 2009; 170:1105-1117. [PubMed: 19808635] 
11. Larson NI, Story MT, Nelson MC. Neighborhood environments: disparities in access to healthy foods in the U. S Am J Prev Med. 2009; 36:74-81.

12. Kumanyika S. Ethnic minorities and weight control research priorities: where are we now and where do we need to be? Prev Med. 2008; 47:583-586. [PubMed: 18955076]

13. Franz MJ, Vanwormer JJ, Crain AL, Boucher JL, Histon T, Caplan W, et al. Weight-loss outcomes: a systematic review and meta-analysis of weight-loss clinical trials with a minimum 1year follow-up. J Am Diet Assoc. 2007; 107:1755-1767. [PubMed: 17904936]

14. Seo DC, Sa J. A meta-analysis of psycho-behavioral obesity interventions among US multiethnic and minority adults. Prev Med. 2008; 47:573-582. [PubMed: 18201758]

15. Yancey AK, Kumanyika SK, Ponce NA, McCarthy WJ, Fielding JE, Leslie JP, et al. Populationbased interventions engaging communities of color in healthy eating and active living: a review. Prev Chronic Dis. 2004; 1:A09. [PubMed: 15634371]

16. West DS, Elaine Prewitt T, Bursac Z, Felix HC. Weight loss of black, white, and Hispanic men and women in the Diabetes Prevention Program. Obesity (Silver Spring). 2008; 16:1413-1420. [PubMed: 18421273]

17. Samuel-Hodge CD, Johnston LF, Gizlice Z, Garcia BA, Lindsley SC, Bramble KP, et al. Randomized trial of a behavioral weight loss intervention for low-income women: the Weight Wise Program. Obesity (Silver Spring). 2009; 17:1891-1899. [PubMed: 19407810]

18. Gustafson A, Khavjou O, Stearns SC, Keyserling TC, Gizlice Z, Lindsley S, et al. Costeffectiveness of a behavioral weight loss intervention for low-income women: the Weight-Wise Program. Prev Med. 2009; 49:390-395. [PubMed: 19747937]

19. Kumanyika SK, Wadden TA, Shults J, Fassbender JE, Brown SD, Bowman MA, et al. Trial of family and friend support for weight loss in African American adults. Arch Intern Med. 2009; 169:1795-1804. [PubMed: 19858438]

20. Befort CA, Nollen N, Ellerbeck EF, Sullivan DK, Thomas JL, Ahluwalia JS. Motivational interviewing fails to improve outcomes of a behavioral weight loss program for obese African American women: a pilot randomized trial. J Behav Med. 2008; 31:367-377. [PubMed: 18587639]

21. Kumanyika S, Fassbender J, Phipps E, Tan-Torres S, Localio R, Morales KH, et al. Design, recruitment and start up of a primary care weight loss trial targeting African American and Hispanic adults. Contemp Clin Trials. 2011; 32:215-224. [PubMed: 21062645]

22. Martin PD, Dutton GR, Rhode PC, Horswell RL, Ryan DH, Brantley PJ. Weight loss maintenance following a primary care intervention for low-income minority women. Obesity (Silver Spring). 2008; 16:2462-2467. [PubMed: 18787526]

23. Drieling RL, Ma J, Stafford RS. Evaluating clinic and community-based lifestyle interventions for obesity reduction in a low-income Latino neighborhood: Vivamos Activos Fair Oaks Program. BMC Public Health. 2011; 11:98. [PubMed: 21320331]

24. Kim KH, Linnan L, Campbell MK, Brooks C, Koenig HG, Wiesen C. The WORD (wholeness, oneness, righteousness, deliverance): a faith-based weight-loss program utilizing a communitybased participatory research approach. Health Educ Behav. 2008; 35:634-650. [PubMed: 17200103]

25. Parker MW, Bellis JM, Bishop P, Harper M, Allman RM, Moore C, et al. A multidisciplinary model of health promotion incorporating spirituality into a successful aging intervention with African American and white elderly groups. Gerontologist. 2002; 42:406-415. [PubMed: 12040144]

26. Hopewell S, Clarke M, Moher D, Wager E, Middleton P, Altman DG, et al. CONSORT for reporting randomized controlled trials in journal and conference abstracts: explanation and elaboration. PLoS Med. 2008; 5:e20. [PubMed: 18215107]

27. Schulz KF, Altman DG, Moher D. CONSORT 2010 statement: updated guidelines for reporting parallel group randomized trials. Ann Intern Med. 152:726-732. [PubMed: 20335313]

28. US Census Bureau. [Accessed December 6, 2010] State \& County Quick Facts. 2000. Available at: http://quickfacts.census.gov/qfd/states/45000.html

29. Adams R. Revised Physical Activity Readiness Questionnaire. Can Fam Physician. 1999; 45:992, 995, 1004-1005. [PubMed: 10216799] 
30. Canadian Society of Exercise Physiology. PAR-Q and You (Physical Activity Readiness Questionnaire (PAR-Q) and Physical Activity Readiness Physical Examination, revised 2002). Gloucester, Ontario: Canadian Society for Exercise Physiology, Health Canada; 1994. p. 1-2.

31. Artinian NT, Fletcher GF, Mozaffarian D, Kris-Etherton P, Van Horn L, Lichtenstein AH, et al. Interventions to promote physical activity and dietary lifestyle changes for cardiovascular risk factor reduction in adults: a scientific statement from the American Heart Association. Circulation. 2010; 122:406-441. [PubMed: 20625115]

32. Bandura, A. Social foundations of thought and action. Englwood Cliffs, NJ: Prentice-Hall; 1986.

33. Heaney, CA.; Israel, BA. Social networks and social support. In: Glanz, K.; Lewis, FM.; Rimer, BK., editors. Health Behavior and Health Education, Theory, Research, and Practice. San Francisco: Jossey-Bass; 1997.

34. Marlatt, GA.; Gordon, JR. Relapse prevention: Maintenance strategies in the treatment of addictive behaviors. New York: Guilford Press; 1985.

35. Appel LJ, Moore TJ, Obarzanek E, Vollmer WM, Svetkey LP, Sacks FM, et al. A clinical trial of the effects of dietary patterns on blood pressure. DASH Collaborative Research Group. N Engl J Med. 1997; 336:1117-1124. [PubMed: 9099655]

36. Bangeman, E. [Accessed June 13, 2011] DVD players finally outnumber VCRs. 2007. Available at: http://arstechnica.com/gadgets/news/2006/12/8484.ars

37. King AC, Baumann K, O'Sullivan P, Wilcox S, Castro C. Effects of moderate-intensity exercise on physiological, behavioral, and emotional responses to family caregiving: a randomized controlled trial. J Gerontol. 2002; 57:M26-36.

38. Parra-Medina D, Wilcox S, Wilson DK, Addy CL, Felton G, Poston MB. Heart Healthy and Ethnically Relevant (HHER) Lifestyle trial for improving diet and physical activity in underserved African American women. Contemp Clin Trials. 2010; 31:92-104. [PubMed: 19781665]

39. Blumberg, SJ.; Luke, JV. [Accessed June 13, 2011] Wireless substitution: Early release of estimates from the National Health Interview Survey, July-December 2010. 2011. Available at: http://www.cdc.gov/nchs/data/nhis/earlyrelease/wireless201106.pdf

40. Joint National Committee on the Prevention D, Evaluation, and Treatment of High Blood Pressure. The Seventh Report of the Joint National Committee on the Prevention, Detection, Evaluation, and Treatment of High Blood Pressure. U.S. Department of health and Human Services, National Institutes of Health, National Heart, Lung, and Blood Institute; 2004.

41. Nord, M.; Andrews, M. [Accessed May 19, 2005] Six-item short form of the Food Security Survey Module. 1999. Available at: www.ers.usda.gov/BReifing/FoodSecurity/surveytools.index.htm\#questionnaire

42. National Health and Nutrition Examination Survey (NHANES). [Accessed October 26, 2010] Anthropometry Procedures Manual. 2007. Available at: http://www.cdc.gov/nchs/data/nhanes/nhanes_07_08/manual_an.pdf

43. Harris MM, Stevens J, Thomas N, Schreiner P, Folsom AR. Associations of fat distribution and obesity with hypertension in a bi-ethnic population: the ARIC study. Atherosclerosis Risk in Communities Study. Obes Res. 2000; 8:516-524. [PubMed: 11068957]

44. Zhu S, Heymsfield SB, Toyoshima H, Wang Z, Pietrobelli A, Heshka S. Race-ethnicity-specific waist circumference cutoffs for identifying cardiovascular disease risk factors. Am J Clin Nutr. 2005; 81:409-415. [PubMed: 15699228]

45. Weber JL, Tinsley AM, Houtkooper LB, Lohman TG. Multimethod training increases portion-size estimation accuracy. J Am Diet Assoc. 1997; 97:176-179. [PubMed: 9020247]

46. Jonnalagadda SS, Mitchell DC, Smiciklas-Wright H, Meaker KB, Van Heel N, Karmally W, et al. Accuracy of energy intake data estimated by a multiple-pass, 24-hour dietary recall technique. $\mathrm{J}$ Am Diet Assoc. 2000; 100:303-308. quiz 309-311. [PubMed: 10719403]

47. Freedson PS, Melanson E, Sirard J. Calibration of the Computer Science and Applications, Inc. accelerometer. Med Sci Sports Exerc. 1998; 30:777-781. [PubMed: 9588623]

48. Matthews CE, Ainsworth BE, Thompson RW, Bassett DR Jr. Sources of variance in daily physical activity levels as measured by an accelerometer. Med Sci Sports Exerc. 2002; 34:1376-1381. [PubMed: 12165695] 
49. Troiano RP, Berrigan D, Dodd KW, Masse LC, Tilert T, McDowell M. Physical activity in the United States measured by accelerometer. Med Sci Sports Exerc. 2008; 40:181-188. [PubMed: 18091006]

50. Masse LC, Fuemmeler BF, Anderson CB, Matthews CE, Trost SG, Catellier DJ, et al. Accelerometer data reduction: a comparison of four reduction algorithms on select outcome variables. Med Sci Sports Exerc. 2005; 37:S544-554. [PubMed: 16294117]

51. Lopes VP, Magalhaes P, Bragada J, Vasques C. Actigraph calibration in obese/overweight and type 2 diabetes mellitus middle-aged to old adult patients. J Phys Act Health. 2009; 6 (Suppl 1):S133-140. [PubMed: 19998859]

52. Jurca R, Jackson AS, LaMonte MJ, Morrow JR Jr, Blair SN, Wareham NJ, et al. Assessing cardiorespiratory fitness without performing exercise testing. Am J Prev Med. 2005; 29:185-193. [PubMed: 16168867]

53. Schlundt DG, Hargreaves MK, Buchowski MS. The Eating Behavior Patterns Questionnaire predicts dietary fat intake in African American women. J Am Diet Assoc. 2003; 103:338-345. [PubMed: 12616256]

54. US Department of Education. [Accessed October 26, 2010] Child Food Consumption Questionnaire. 2004. Available at: http://nces.ed.gov/ecls/pdf/fifthgrade/childfoodconsumption.pdf

55. Garcia AW, King AC. Predicting long-term adherence to aerobic exercise: A comparison of two models. Journal of Sport and Exercise Psychology. 1991; 13:394-410.

56. Wilcox S, Sharpe PA, Hutto B, Granner ML. Psychometric properties of the Self-Efficacy for Exercise Questionnaire in a diverse sample of men and women. J Phys Act Health. 2005; 2:285297.

57. Chang MW, Nitzke S, Brown RL, Baumann LC, Oakley L. Development and validation of a selfefficacy measure for fat intake behaviors of low-income women. J Nutr Educ Behav. 2003; 35:302-307. [PubMed: 14642215]

58. Sharpe, PA.; Rooney, LJ.; Wilcox, S.; Hutto, B. Measuring social interaction for exercise, healthy eating and weight control among middle-aged women. under review

59. Nies MA, Hepworth JT, Wallston KA, Kershaw TC. Evaluation of an instrument for assessing behavioral change in sedentary women. J Nurs Scholarsh. 2001; 33:349-354. [PubMed: 11775305]

60. Irwin M, Artin KH, Oxman MN. Screening for depression in the older adult: criterion validity of the 10-item Center for Epidemiological Studies Depression Scale (CES-D). Arch Intern Med. 1999; 159:1701-1704. [PubMed: 10448771]

61. Radloff LS. The CES-D scale: a self-report depression scale for research in the general population. App Psych Measure. 1977; 1:385-401.

62. Linnan, L.; Steckler, A. Process evaluation for public health interventions and research, an overview. In: Steckler, A.; Linnan, L., editors. Process evaluation for public health interventions and research. San Francisco: Jossey-Bass; 2002. p. 1-23.

63. Singer, JD.; Willett, JB. Applied longitudinal data analysis: Modeling change and event occurrence. Oxford University Press; 2003.

64. Little R, Yau L. Intent-to-treat analysis for longitudinal studies with drop-outs. Biometrics. 1996; 52:1324-1333. [PubMed: 8962456]

65. Baranowski T, Anderson C, Carmack C. Mediating variable framework in physical activity interventions: How are we doing? How might we do better? Am J Prev Med. 1998; 15:266-297. [PubMed: 9838973]

66. MacKinnon D, Lockwood C, Williams J. Confidence limits for the indirect effect: distribution of the product and resampling methods. Multivariate Behavioral Research. 2004; 39:99-128. [PubMed: 20157642]

67. MacKinnon DP, Fritz MS, Williams J, Lockwood CM. Distribution of the product confidence limits for the indirect effect: program PRODCLIN. Behav Res Methods. 2007; 39:384-389. [PubMed: 17958149]

68. MacKinnon DP, Lockwood CM, Hoffman JM, West SG, Sheets V. A comparison of methods to test mediation and other intervening variable effects. Psychol Methods. 2002; 7:83-104. [PubMed: 11928892] 


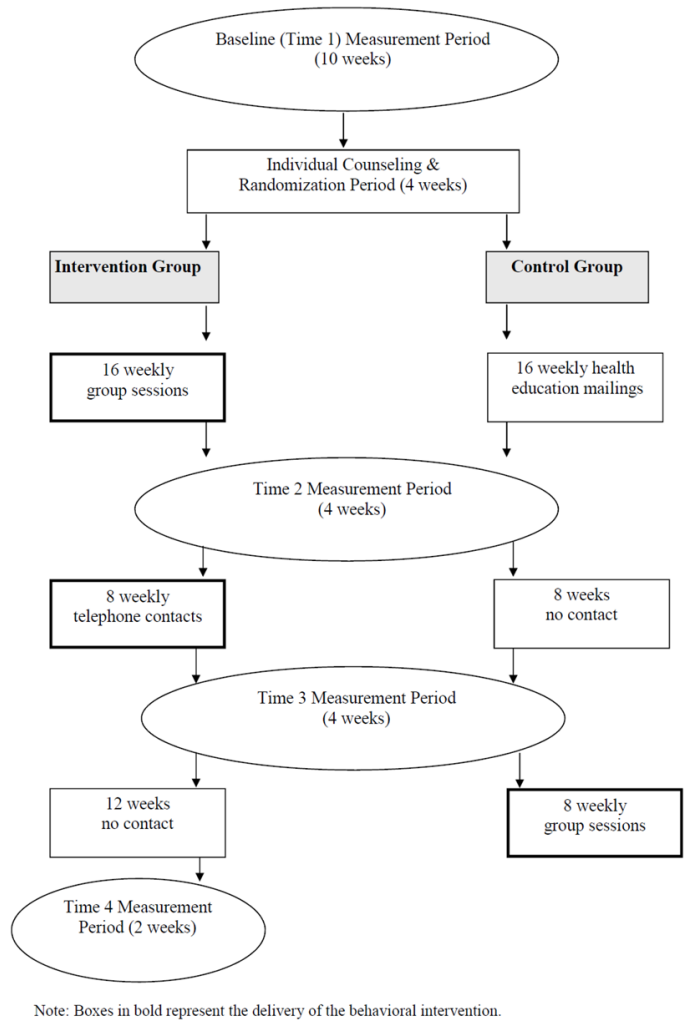

Figure 1.

STARS Study Design

Note: Boxes in bold represent the delivery of the behavioral intervention. 


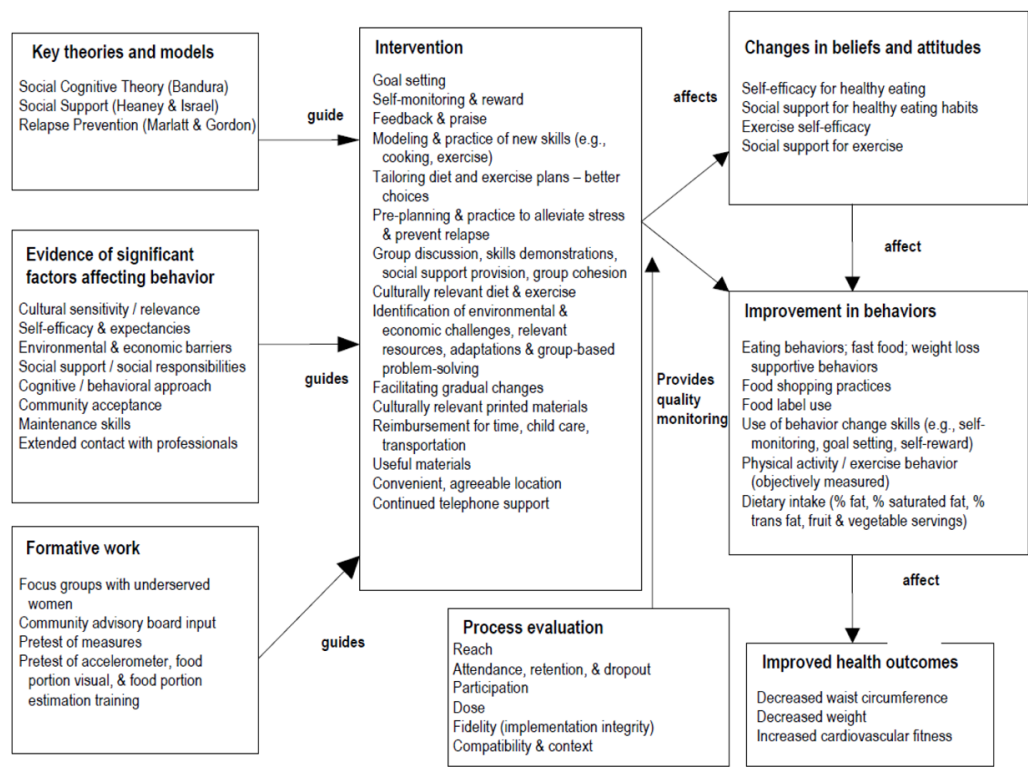

Figure 2.

Model of a behavioral/support intervention for underserved women to promote healthy diet and exercise for weight loss 


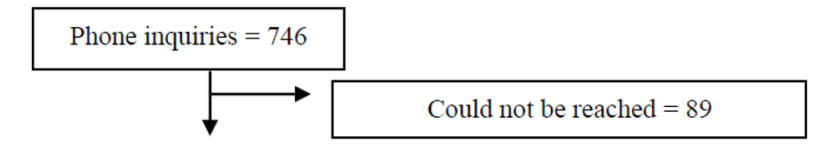

Completed telephone screening $=657$

Ineligible $=350$

232 Resided outside of target Census tracts

59 Not in age range

23 Logistics/schedule conflict

21 Not overweight

12 Medical contraindication

3 Living arrangements

Scheduled for baseline visit $=307$

Did not attend baseline visit $=77$

Attended baseline visit and signed consent form $=230$

Excluded due to medical contraindication $=1$

Completed baseline visit $=229$

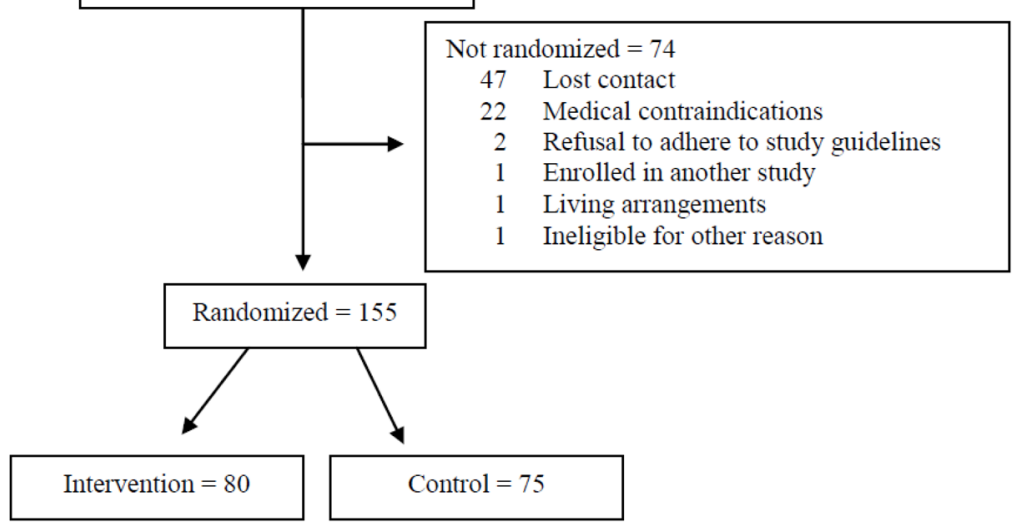

Figure 3.

STARS Recruitment flow chart 
Table 1

Outline of the Topics Covered in the 16-Week Group Sessions

\begin{tabular}{|c|c|c|}
\hline Session & Topics & Behavioral Skills or Strategies \\
\hline 1 & $\begin{array}{ll}\text { - } & \text { Introduction to writing objectives } \\
\text { - } & \text { Exercise overview (with group exercise) } \\
\text { - } & \text { Diet overview }\end{array}$ & $\begin{array}{ll}\text { - } & \text { Self-regulation: self-monitoring, setting goals, \& self- } \\
\text { reward } \\
\text { - } & \text { Knowledge/self-efficacy } \\
\text { - } & \text { Knowledge }\end{array}$ \\
\hline 2 & $\begin{array}{ll}\text { - } & \text { Writing objectives } \\
\text { - } & \text { Staying Safe when Exercising Outdoors } \\
\text { - } & \text { Counting your Steps (with group exercise) }\end{array}$ & $\begin{array}{ll}\text { - } & \text { Self-regulation: self-monitoring, setting goals, \& self- } \\
\text { reward } \\
\text { - } & \text { Behavioral capacity } \\
\text { - } & \begin{array}{l}\text { Self-monitoring/goal setting/behavioral capacity/self- } \\
\text { efficacy }\end{array}\end{array}$ \\
\hline 3 & $\begin{array}{ll}\text { - } & \text { Eating More Vegetables } \\
\text { - } & \text { Meal Planning } \\
\text { - } & \text { Food demo \& tasting }\end{array}$ & $\begin{array}{ll}\text { - } & \text { Behavioral capacity } \\
\text { - } & \text { Behavioral capacity (planning) } \\
\text { - } & \text { Behavioral capacity/self-efficacy }\end{array}$ \\
\hline 4 & $\begin{array}{ll}\text { - } & \text { Aerobic Activity (with group exercise) } \\
\text { - } & \text { Eating More Fruits } \\
\text { - } & \text { Food demo \& tasting }\end{array}$ & $\begin{array}{ll}\text { - } & \text { Behavioral capacity/self-efficacy } \\
\text { - } & \text { Behavioral capacity } \\
\text { - } & \text { Behavioral capacity/self-efficacy }\end{array}$ \\
\hline 5 & $\begin{array}{ll}\text { - } & \text { Dealing with Triggers } \\
\text { - } & \text { Eating More Whole Grains } \\
\text { - } & \text { Food demo \& tasting }\end{array}$ & $\begin{array}{ll}\text { - } & \text { Stimulus control/barriers } \\
\text { - } & \text { Behavioral capacity } \\
\text { - } & \text { Behavioral capacity/self-efficacy }\end{array}$ \\
\hline 6 & $\begin{array}{ll}\text { - } & \text { Modifying Recipes: ROSE Method } \\
\text { - } & \text { Food demo \& tasting (group meal) }\end{array}$ & $\begin{array}{ll}\text { - } & \text { Behavioral capacity (cooking substitutions) } \\
\text { - } & \text { Behavioral capacity/self-efficacy }\end{array}$ \\
\hline 7 & $\begin{array}{ll}\text { - } & \text { Avoiding Roadblocks } \\
\text { - } & \text { Managing Stress }\end{array}$ & $\begin{array}{ll}\text { - } & \text { Problem solving/relapse prevention } \\
\text { - } & \text { Stress management }\end{array}$ \\
\hline 8 & $\begin{array}{ll}\text { - } & \text { Target Heart Rate (with group exercise) } \\
\text { - } & \text { Reading Food Labels } \\
\text { - } & \text { How to Shop and Eat Right }\end{array}$ & $\begin{array}{ll}\text { - } & \text { Behavioral capacity (gauging intensity) } \\
\text { - } & \text { Behavioral capacity (label reading) } \\
\text { - } & \text { Behavioral capacity (planning \& shopping) }\end{array}$ \\
\hline 9 & - $\quad$ Supermarket Tour & - $\quad$ Behavioral capacity (shopping)/self- efficacy \\
\hline 10 & 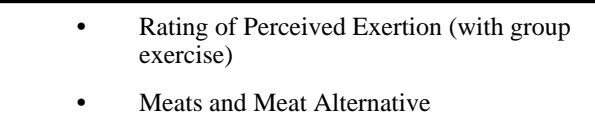 & $\begin{array}{l}\text { - } \quad \text { Behavioral capacity (gauging intensity)/self-efficacy } \\
\text { - } \quad \text { Behavioral capacity }\end{array}$ \\
\hline 11 & $\begin{array}{ll}\text { - } & \text { Flexibility (with group exercise) } \\
\text { - } & \text { Dairy/Calcium } \\
\text { - } & \text { Food demo \& tasting }\end{array}$ & $\begin{array}{ll}\text { - } & \text { Behavioral capacity/self-efficacy } \\
\text { - } & \text { Behavioral capacity } \\
\text { - } & \text { Behavioral capacity/self-efficacy }\end{array}$ \\
\hline 12 & - $\quad$ Community Resources & - $\quad$ Environmental opportunities \\
\hline
\end{tabular}




\begin{tabular}{|c|c|c|}
\hline Session & Topics & Behavioral Skills or Strategies \\
\hline 13 & $\begin{array}{ll}\text { - } & \text { Resistance Training (with group exercise) } \\
\text { - } & \text { Eating Out }\end{array}$ & $\begin{array}{ll}\text { - } & \text { Behavioral capacity/self-efficacy } \\
\text { - } & \text { Behavioral capacity/self-monitoring }\end{array}$ \\
\hline 14 & $\begin{array}{ll}\text { - } & \text { Relapse Prevention } \\
\text { - } & \text { Keeping your Motivation to Exercise } \\
\text { - } & \text { What's Next for Exercise }\end{array}$ & $\begin{array}{ll}\text { - } & \text { Relapse prevention \& cognitive restructuring } \\
\text { - } & \text { Motivation \& reward } \\
\text { - } & \text { Motivation \& reward }\end{array}$ \\
\hline 15 & $\begin{array}{ll}\text { - } & \text { Social Support } \\
\text { - } & \text { Yoga (with group exercise) }\end{array}$ & $\begin{array}{l}\text { - Instrumental, appraisal, emotional, \& informational social } \\
\text { support/assertiveness training } \\
\text { - } \quad \text { Behavioral capacity/self-efficacy }\end{array}$ \\
\hline 16 & $\begin{array}{l}\text { - } \\
\text { - } \\
\text { - } \\
\text { Geview of Skills and What Workedise: dancing } \\
\text { Celion }\end{array}$ & - $\quad$ Review of behavioral skills \\
\hline
\end{tabular}

Note: Each session started with group sharing and support (problem solving) and recording of daily steps and minutes of exercise (self-monitoring). Each session concluded with setting weekly goals/objectives in participant's journal (goal setting). A healthy snack was provided in each session that did not contain a food demonstration and tasting (except for session 9). 
Table 2

Baseline Characteristics of Study Participants, Overall and by Group Assignment

\begin{tabular}{|c|c|c|c|}
\hline Characteristic & Intervention $(\mathrm{n}=\mathbf{8 0})$ & Control $(n=75)$ & Total Sample $(\mathrm{N}=155)$ \\
\hline \multicolumn{4}{|l|}{ Race, \% (n) } \\
\hline White & $6.3(5)$ & $10.7(8)$ & $8.4(13)$ \\
\hline Black/African American & $87.5(70)$ & $85.3(64)$ & $86.5(134)$ \\
\hline$>1$ category & $6.3(5)$ & $4.0(3)$ & $5.2(8)$ \\
\hline \multicolumn{4}{|l|}{ Hispanic ethnicity, \% (n) } \\
\hline Yes & $2.5(2)$ & $2.7(2)$ & $2.6(4)$ \\
\hline No & $97.5(78)$ & $96.0(72)$ & $96.8(150)$ \\
\hline Missing & $0.0(0)$ & $1.3(1)$ & $0.6(1)$ \\
\hline Age in years, Mean $\pm \mathrm{SD}$ & $38.6 \pm 7.2$ & $39.3 \pm 7.9$ & $38.9 \pm 7.5$ \\
\hline \multicolumn{4}{|l|}{ Education, \% (n) } \\
\hline Never attended school & $0.0(0)$ & $0.0(0)$ & $0.0(0)$ \\
\hline Grades $1-8$ & $0.0(0)$ & $1.3(1)$ & $0.7(1)$ \\
\hline Grades 9-11 & $2.5(2)$ & $8.0(6)$ & $5.2(8)$ \\
\hline Grade 12 or GED & $11.3(9)$ & $14.7(11)$ & $12.9(20)$ \\
\hline Some college & $48.8(39)$ & $49.3(37)$ & $49.0(76)$ \\
\hline College grad & $37.5(30)$ & $26.7(20)$ & $32.3(50)$ \\
\hline \multicolumn{4}{|l|}{ Insurance, $\%(\mathrm{n})$} \\
\hline Yes & $77.5(62)$ & $82.7(62)$ & $80.0(124)$ \\
\hline No & $22.5(18)$ & $17.3(13)$ & $20.0(31)$ \\
\hline \multicolumn{4}{|l|}{ Marital status, \% (n) } \\
\hline Married & $25.0(20)$ & $20.0(15)$ & $22.6(35)$ \\
\hline Divorced & $21.3(17)$ & $17.3(13)$ & $19.4(30)$ \\
\hline Widowed & $1.3(1)$ & $1.3(1)$ & $1.3(2)$ \\
\hline Separated & $6.3(5)$ & $9.3(7)$ & $7.7(12)$ \\
\hline Never married & $42.5(34)$ & $37.3(28)$ & $40.0(62)$ \\
\hline Couple & $3.8(3)$ & $14.7(11)$ & $9.0(14)$ \\
\hline \multicolumn{4}{|l|}{ Employment status, \% (n) } \\
\hline Employed & $75.0(60)$ & $77.3(58)$ & $76.1(118)$ \\
\hline Not employed & $10.0(8)$ & $12.0(9)$ & $11.0(17)$ \\
\hline Student & $6.3(5)$ & $5.3(4)$ & $5.8(9)$ \\
\hline Retired & $1.3(1)$ & $1.3(1)$ & $1.3(2)$ \\
\hline Unable to work & $2.5(2)$ & $2.7(2)$ & $2.6(4)$ \\
\hline Employed and student & $5.0(4)$ & $1.3(1)$ & $3.2(5)$ \\
\hline Number of children in household, Mean \pm SD & $1.10 \pm 1.32$ & $0.81 \pm 0.97$ & $0.96 \pm 1.17$ \\
\hline \multicolumn{4}{|l|}{ Number of children in household, \% (n) } \\
\hline 0 & $48.8(39)$ & $49.3(37)$ & $49.0(76)$ \\
\hline 1 & $17.5(14)$ & $26.7(20)$ & $21.9(34)$ \\
\hline 2 & $15.0(12)$ & $18.7(14)$ & $16.8(26)$ \\
\hline 3 & $13.8(11)$ & $4.0(3)$ & $9.0(14)$ \\
\hline
\end{tabular}




\begin{tabular}{|c|c|c|c|}
\hline Characteristic & Intervention $(\mathrm{n}=\mathbf{8 0})$ & Control (n=75) & Total Sample $(\mathrm{N}=155)$ \\
\hline 4 or 5 & $5.0(4)$ & $1.3(1)$ & $3.2(5)$ \\
\hline \multicolumn{4}{|l|}{ Food Insecurity, \% (n) } \\
\hline Secure & $52.5(42)$ & $62.7(47)$ & $57.4(89)$ \\
\hline Insecure w/o hunger & $31.3(25)$ & $29.3(22)$ & $30.3(47)$ \\
\hline Insecure with hunger & $16.3(13)$ & $8.0(6)$ & $12.3(19)$ \\
\hline Weight in pounds, Mean \pm SD & $242.1 \pm 62.7$ & $234.3 \pm 53.6$ & $238.4 \pm 58.4$ \\
\hline BMI $\left(\mathrm{kg} / \mathrm{m}^{2}\right)$, Mean $\pm \mathrm{SD}$ & $40.4 \pm 9.8$ & $39.7 \pm 8.2$ & $40.1 \pm 9.1$ \\
\hline \multicolumn{4}{|l|}{ BMI category, \% (n) } \\
\hline $\mathrm{BMI}<25 \mathrm{~kg} / \mathrm{m} 2$ & $0.0(0)$ & $0.0(0)$ & $0.0(0)$ \\
\hline BMI $25.0-29.9 \mathrm{~kg} / \mathrm{m} 2$ & $6.3(5)$ & $6.7(5)$ & $6.5(10)$ \\
\hline $\mathrm{BMI} \geq 30.0 \mathrm{~kg} / \mathrm{m} 2$ & $93.7(75)$ & $93.3(70)$ & $93.5(145)$ \\
\hline Waist circumference, \% (n) & $116.0 \pm 18.7$ & $114.7 \pm 17.1$ & $115.4 \pm 17.9(155)$ \\
\hline \multicolumn{4}{|c|}{ Self-reported health conditions Heart condition, \% (n) } \\
\hline Yes & $8.8(7)$ & $10.7(8)$ & $9.7(15)$ \\
\hline No & $91.2(73)$ & $89.3(67)$ & $90.3(140)$ \\
\hline \multicolumn{4}{|l|}{ Cancer, \% (n) } \\
\hline Yes & $3.8(3)$ & $0.0(0)$ & $1.9(3)$ \\
\hline No & $96.2(77)$ & $100.0(75)$ & $98.1(152)$ \\
\hline \multicolumn{4}{|l|}{ Diabetes, \% (n) } \\
\hline Yes & $10.0(8)$ & $8.0(6)$ & $9.0(14)$ \\
\hline No & $90.0(72)$ & $92.0(69)$ & $91.0(141)$ \\
\hline \multicolumn{4}{|l|}{ Hypertension, \% (n) } \\
\hline Yes & $31.3(25)$ & $21.3(16)$ & $26.5(41)$ \\
\hline No & $68.7(55)$ & $78.7(59)$ & $73.5(114)$ \\
\hline \multicolumn{4}{|l|}{ Arthritis, \% (n) } \\
\hline Yes & $16.3(13)$ & $10.7(8)$ & $13.6(21)$ \\
\hline No & $83.8(67)$ & $89.3(67)$ & $86.4(134)$ \\
\hline
\end{tabular}

